\title{
Adaptación de bacterias a diferentes concentraciones de fenol en el laboratorio: aspectos esenciales para un proceso de biodegradación
}

\section{Gustavo Echeverri Jaramillo'}

\begin{abstract}
1. Universidad San Buenaventura-Cartagena. Programa de Bacteriología. Facultad Ciencias de la Salud. Docente-Investigador. Líder Grupo de Investigación Microbiología y Ambiente, GIMA.

Correspondencia: gecheverri@usbctg.edu.co
\end{abstract}

Recibido: 11/11/2011 - Aceptado: 20/12/2011

\begin{abstract}
Resumen
En el presente trabajo se determino la carga bacteriana de muestras de agua y suelo contaminadas con diferentes concentraciones de fenol. Se hizo seguimiento en medio mineralizado con concentraciones de 200 a $10000 \mathrm{mg} / \mathrm{L}$ y variaciones de inoculo. Se evidenciaron cambios en crecimiento bacteriano, encontrándose mayor carga en suelo con fase de adaptación al segundo día y fase de crecimiento en cuarto día. Comparando variaciones del inoculo (directa, adaptado y preenriquecimiento) el directo puede aplicarse para muestras de carga alta (suelo); el preenriquecimiento no es práctico por el estrés bacteriano y adaptado permite ser usado hasta $500 \mathrm{mg} / \mathrm{L}$ sin problemas. En repiques sobre agares (mineralizados y nutritivo) hubo crecimiento hasta $1000 \mathrm{mg} / \mathrm{L}$. Es importante para depurar aguas residuales, encontrar bacterias de diferentes fuentes que resistan altas concentraciones de fenol y permitan efectividad en bioprocesos al estudiar comportamientos de pre adaptación, tiempos y tratamientos adecuados para la preparación del inóculo.

Palabras clave: biodegradación de fenol, bioremediación, biotecnología ambiental, bacterias degradadoras, ambiente marino.
\end{abstract}

\section{Abstract \\ Adaptation of bacteria to different concentrations of phenol in the laboratory: essentials for biodegradation process}

It was intended to see growth of bacterial load of contaminated samples, based on adaptation to different concentrations of phenol. Were followed in the middle mineralized concentrations (200 to l 0000 mg/L), and variations of inoculum. Demonstrated changes in bacterial growth, increased burden found in soil, with phase adjustment on the second day and growth phase on the third day, most clearly in 200 and $500 \mathrm{mg} / \mathrm{L}$, decreasing with increasing concentration. Comparing variations in the inoculums (directly adapted and pre-enrichment), the samples can be applied to direct high load (soil), the pre-enrichment is not practical for bacterial stress, can be used and adapted to $500 \mathrm{mg} / \mathrm{L}$ with no problems. In ringing on agar (mineralized and nutritious), there was growth up to $1000 \mathrm{mg} / \mathrm{L}$, making it clear toal low detailed study biochemical characterization. It is important to purify waste water from different sources to find bacteria that resist high concentrations of phenol and 
allow effective ness in bioprocesses, knowing preadaptation behaviors, such as study time and appropriate treatment for the preparation of inoculum.

Keywords: biodegradation of phenol, bioremediation, environmental biotechnology, degrading bacteria, marine environment.

\section{Introducción}

El fenol es una sustancia química mono aromática derivada del benceno, conocido como alcohol monohidroxilico, con un grupo hidroxilo u oxidrilo, de masa cristalina incolora o ligeramente amarilla/ rosada, de fuerte olor característico, cáustico y toxico. Soluble en agua y en solventes orgánicos como éter, alcohol y acetona. Es un desinfectante general y en soluciones diluidas, es usado como preservante, antiprurítico o anestésico local. Es usado en la fabricación de una variedad de productos, como resinas sintéticas, plásticos, reveladores fotográficos, goma, pesticidas y colorantes. Tanto en su producción, y en su uso como materia prima en diferentes procesos productivos (refinería de petróleo, resinas sintéticas, manufactura de explosivos), es vertido en aguas residuales, lo que implica hacer medidas preventivas en su descarga a alcantarillados, como a cuerpos de agua (1).

Las aguas residuales de diferentes procesos industriales pueden variar entre $10 \mathrm{mg} / \mathrm{L}$ y $3000 \mathrm{mg} / \mathrm{L}$, incluso hasta $4000 \mathrm{mg} / \mathrm{L}$, lo que hace que su remoción sea relevante, a través de diferentes procesos, contemplando los valores estándares de la EPA de menos $1 \mathrm{ug} / \mathrm{L}$ (1ppb) al ser descargado, o descargas determinadas por otros autores de $0.5 \mathrm{mg} / \mathrm{L} \mathrm{a}$ $1.0 \mathrm{mg} / \mathrm{L}$, como aguas de plantas industriales con concentraciones que estén por debajo de $50 \mathrm{mg} / \mathrm{L}$; el uso de técnicas físico químicas, como la extracción con solventes, la oxidación química, la adsorción e incineración, cloración, ozonización, procesos de membrana, coagulación, floculación, entre otros, han sido utilizadas para este propósito. Así mismo, el tratamiento biológico despierta gran interés por su bajo costo, su efectividad y su bajo impacto ecológico. Técnicas biológicas se han usado para el tratamiento de suelos y aguas residuales con concentraciones moderadas de fenol que van de
$5 \mathrm{mg} / \mathrm{L}$ a $500 \mathrm{mg} / \mathrm{L}(1-9)$. El uso de microorganismos para la degradación de fenol ha sido muy estudiado, encontrando en la literatura una gran cantidad de microorganismos con este potencial. Los procesos aeróbicos para el tratamiento biológico son preferidos, por su bajo costo y por permitir mineralización completa de la sustancia a degradar (10).

Es de gran importancia para la depuración de aguas residuales contaminadas con fenol encontrar microorganismos aislados de diferentes fuentes que puedan resistir altas concentraciones de fenol, permitiendo que los procesos puedan ser más efectivos. El uso de cultivos puros de microorganismos adaptados a la sustancia problema a metabolizar es una alternativa muy atractiva (4); para esto, se debe tener en cuenta la adaptación de células microbianas a altas concentraciones de fenol, la inmovilización de células y la adición de otras fuentes de carbono, como el extracto de levadura y la glucosa $(4,11$, 12,1,6). La pre adaptación de microorganismos a compuestos aromáticos como benceno y tolueno ha incrementado la degradación de fenol confirmándose cambios en membrana celular, inducción de enzimas intracelulares (12).

La aclimatación de bacterias en diferentes concentraciones de las sustancias a remediar, es un paso importante en los procesos de tratamiento biológicos (13), encontrándose la adaptación de microorganismos en medios mineralizados con concentraciones de fenol entre 300 y $2000 \mathrm{mg} / \mathrm{L}$ (14). La adaptación de Nocardiahydrocarbonoxydans a concentración de fenol de $500 \mathrm{mg} / \mathrm{L}$ para su inmovilización y remoción en un reactor de lecho (15), como también una aclimatación que varió de $100 \mathrm{mg} / \mathrm{L}$ a $900 \mathrm{mg} / \mathrm{L}$ en un tiempo de 15 días buscando una tolerancia limite que fue de $900 \mathrm{mg} / \mathrm{L}$ con el mismo microorganismo (15). Se estableció una aclimatación de Bacillus brevis en medio mínimo con una concentración de fenol inicial de $500 \mathrm{mg} / \mathrm{L}$, y adiciones incrementales a $750 \mathrm{mg} / \mathrm{L}$, $1500 \mathrm{mg} / \mathrm{L}$ y $1750 \mathrm{mg} / \mathrm{L}(8)$. 
Esta investigación pretendió ver el crecimiento de carga bacteriana de muestras de agua y suelo contaminadas, basadas en su adaptación a diferentes concentraciones de fenol. Se hizo un seguimiento en medio mineralizado con diferentes concentraciones de fenol $(200 \mathrm{a} 10000 \mathrm{mg} / \mathrm{L})$ y variaciones en inoculo (directa, adaptada y pre enriquecimiento), aspecto no analizado en las revisiones previas.

\section{Materiales y métodos}

\section{Medios de cultivo y reactivos}

Se utilizó caldo nutritivo, agar nutritivo y agar-agar de casa comercial, los cuales fueron preparados según las instrucciones del fabricante. El medio mineralizado liquido fue preparado con sales grado reactivo; el medio mineralizado sólido se obtuvo agregando agar-agar a $15 \mathrm{~g} / \mathrm{l}$ fenol grado reactivo. Los medios fueron esterilizados en autoclave para garantizar completa esterilidad.

\section{Fuente y preparación de muestras}

Se seleccionaron 2 tipos de muestras como fuente de bacterias que permitieran y garantizaran su aislamiento en condiciones previas de tolerancia química basada en hidrocarburos, así:

Muestra liquida. Caldo de pre-enriquecimiento de un estudio previo $\left(\mathrm{NH}_{4} \mathrm{H}_{2} \mathrm{PO}_{4} 0.9 \mathrm{mg} / \mathrm{l}+1 \%\right.$ de ACPM) en tubos con tapa rosca ( $9 \mathrm{ml}$ de caldo + $1 \mathrm{ml}$ muestra de agua) sembrados con aguas marinas de diferentes ecosistemas de la Bahía de Cartagena y cercanos a una industria petroquímica, almacenados 60 días para hacer una mezcla en partes iguales y disponer de un inoculo de $1 \mathrm{ml}$ para procedimientos posteriores en este estudio (16).

Muestra sólida. Suelo contaminado con aceites y gasolinas en cercanías a un taller automotriz. Se tomó con pala manual $400 \mathrm{~g}$ de muestra de suelo: $1 \mathrm{~g}$ de muestra en $9 \mathrm{ml}$ de agua destilada, en agitación constante y posterior reposo.

Seguimiento al crecimiento bacteriano. Para este procedimiento se tuvieron 3 variaciones, al sembrar la muestra líquida y la muestra sólida en el medio líquido, así:

Siembra al mismo tiempo de la muestra líquida y sólida sobre medio mineralizado con concentración
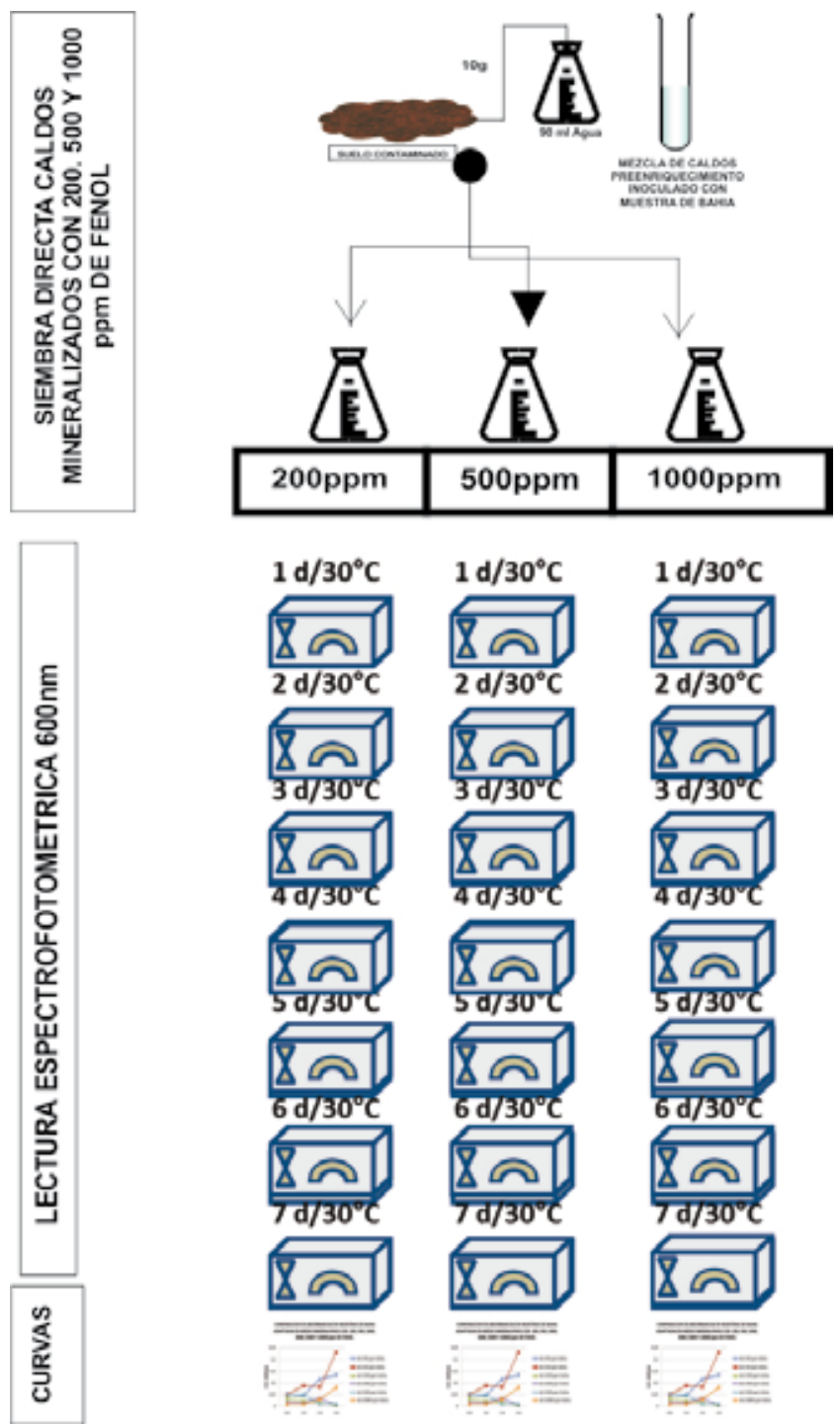

Figura 1. Procedimientos para el crecimiento bacteriano en concentraciones de 200, 500 y $1000 \mathrm{mg} / \mathrm{L}$ de Fenol y Directo.

de fenol de $200 \mathrm{mg} / \mathrm{L}, 500 \mathrm{mg} / \mathrm{L}$ y $1000 \mathrm{mg} / \mathrm{L}$ a la que se llamó "directa". Se sembró $1 \mathrm{ml}$ de cada muestra en un erlenmeyer con $50 \mathrm{ml}$ de medio mineralizado. Se incubaron a $30^{\circ} \mathrm{C}$ por 7 días, con revisión y agitación diaria. Se tomo una alícuota de $2 \mathrm{ml}$ para hacer lectura espectrofotométrica a $600 \mathrm{~nm}$ por duplicado, a las 24 , 48, 72, 96, 120, 144 y 168 horas (7 días), Figura 1.

Siembra de la muestra líquida y sólida sobre medio mineralizado con concentración de fenol de $200 \mathrm{mg} / \mathrm{L}$ a la que se llamó "adaptada". Se sembró $1 \mathrm{ml}$ de cada muestra en un erlenmeyer con fenol de $200 \mathrm{mg} / \mathrm{L}$ y $50 \mathrm{ml}$ de medio mineralizado. Se incubaron a $30^{\circ} \mathrm{C}$ por 3 días, con revisión y agitación diaria y toma de una alícuota de $2 \mathrm{ml}$ para hacer lectura espectrofotométrica a $600 \mathrm{~nm}$ por duplicado, a las 24 , 
48 y 72 horas. Este procedimiento se repitió en las concentraciones de fenol de 500, 1000, 3000, 5000 y $10000 \mathrm{mg} / \mathrm{L}$, Figura 2.

Siembra de la muestra líquida y sólida sobre caldo nutritivo, a la que se llamó "preenriquecimiento". Se sembró $1 \mathrm{ml}$ de cada muestra en un erlenmeyer con $50 \mathrm{ml}$ de caldo nutritivo. Se incubaron las muestras a $30^{\circ} \mathrm{C}$ por 24 horas. Se sembró $1 \mathrm{ml}$ de cada muestra pre enriquecida en caldo nutritivo en un erlenmeyer, que contenía la concentración de fenol de $200 \mathrm{mg} / \mathrm{L}$ y $50 \mathrm{ml}$ de medio mineralizado. Se incubaron los tubos a $30^{\circ} \mathrm{C}$ por 3 días, con revisión y agitación diaria y se tomo una alícuota de $2 \mathrm{ml}$ para hacer lectura espectrofotométrica a $600 \mathrm{~nm}$ por duplicado, a las 24 , 48 y 72 horas. Este procedimiento se repitió en las concentraciones de fenol de 500, 1000, 3000, 5000 y $10000 \mathrm{mg} / \mathrm{L}$, Figura 2.

-Screening de crecimiento bacteriano en medios sólidos para el aislamiento y recuento de microorganismos pre adaptados a las diferentes concentraciones de fenol descritas anteriormente. Se partió de los crecimientos en medio mineralizado sembrados con muestra liquida (bahía) y muestra sólida (suelo), con procedimiento de muestras "adaptadas" y de "preenriquecimiento" así:

Repiques de los erlenmeyer, que contenían $50 \mathrm{ml}$ de caldo mineralizado con procedimiento "adaptado" sobreagar mineralizado y en agar nutritivo con concentraciones de fenol de 200, 500, 1000, 3000, 5000 y $10000 \mathrm{mg} / \mathrm{L}$, al finalizar las 72 horas de incubación de cada una de las concentraciones se tomaron $100 \mathrm{ul}$ con micro pipeta utilizando puntas estériles y se procedió a dispersar en toda la caja con un asa metálica. Se incubaron las cajas a $30^{\circ} \mathrm{C}$, revisando los crecimientos diariamente por tres días, Figura 3.

Recuento de microorganismos de todos los erlenmeyer con caldo mineralizado con procedimiento "adaptado" y de "preenriquecimiento" en agar nutritivo, una vez terminado el tiempo de incubación de todas las concentraciones de fenol desde $200 \mathrm{mg} / \mathrm{L}$ hasta $10000 \mathrm{mg} / \mathrm{L}$. Se tomaron $100 \mathrm{ul}$ y se colocaron en caja de petri previo al vertido de agar nutritivo por técnica de siembra a profundidad, homogenizándose con rotaciones constantes hasta su solidificación e incubación a $30^{\circ} \mathrm{C}$ por 24 horas, Figura 4 .

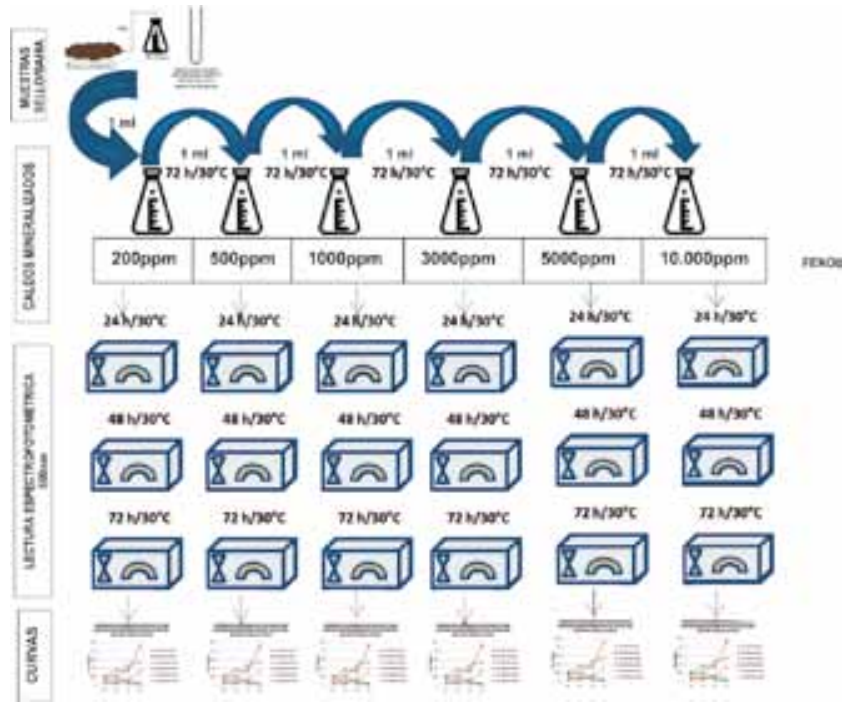

Figura 2. Procedimientos para el crecimiento bacteriano en concentraciones de 200, 500, 1000, 3000, 5000 y 10000mg/L de Fenol y Adaptado-Pre enriquecimiento.

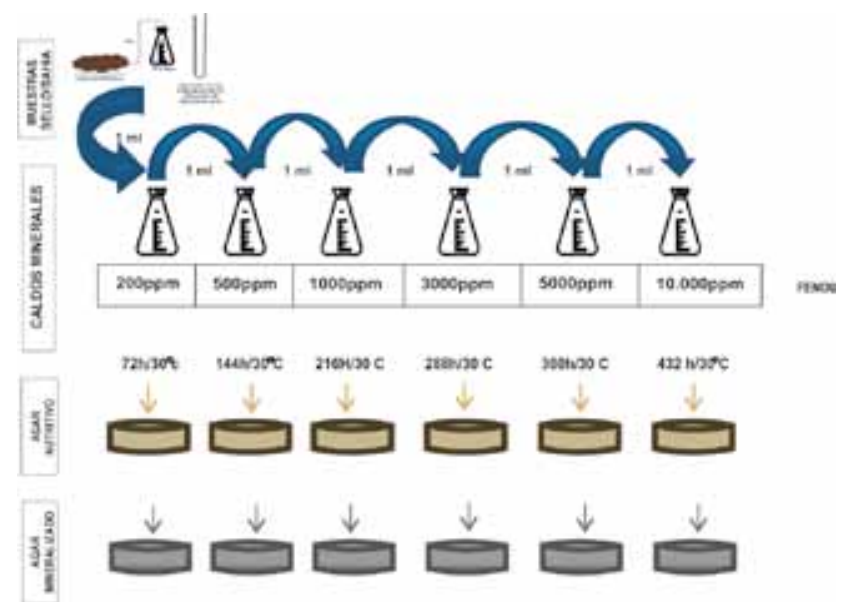

Figura 3. Procedimientos para el crecimiento bacteriano en medios sólidos con concentraciones de 200, 500, 1000, 3000, 5000 y $10000 \mathrm{mg} / \mathrm{L}$ y Adaptado.

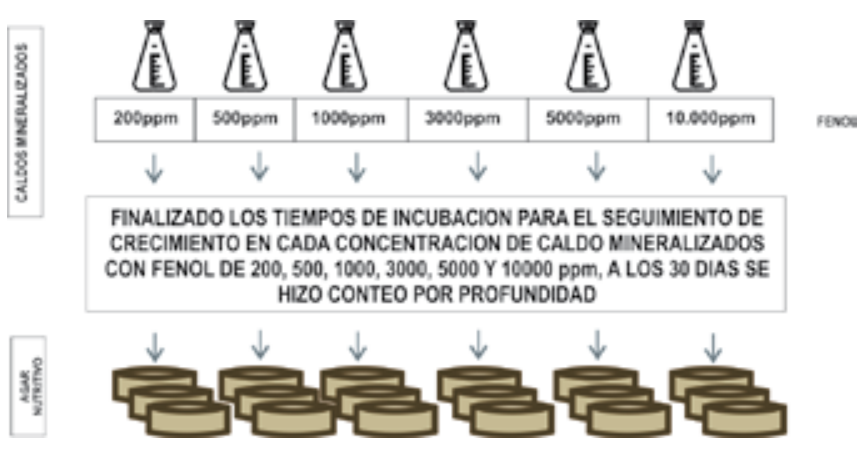

Figura 4. Procedimientos para el seguimiento de crecimiento bacteriano en medios sólidos con concentraciones de 200, 500, 1000, 3000, 5000 y $10000 \mathrm{mg} / \mathrm{L}$ en Adaptado y Preenriquecimiento. 


\section{Resultados}

Crecimiento bacteriano sobre caldo mineralizado con diferentes concentraciones de fenol. En concentraciones de 200,500 y $1000 \mathrm{mg} / \mathrm{L}$ de fenol y procedimiento "directo"se hizo un seguimiento durante 7 días. Se observan mayores absorbancias en las muestras originadas de suelo, comparadas con las muestras de agua (bahía), se observó un aumento considerable de absorbancia a la concentración de $200 \mathrm{mg} / \mathrm{L}$, mientras que el aumento al quinto día se vio a $500 \mathrm{mg} / \mathrm{L}$; en la concentración de $1000 \mathrm{mg} / \mathrm{L}$, hubo coherencia en la absorbancia hasta el tercer día, presentando picos de crecimiento Figura 5.

Al comparar los datos de las absorbancias de las siembras “directas", “adaptadas" "preenriquecimiento", en 24, 48 y 72 horas de incubación con concentraciones de fenol de 200, 500 y $1000 \mathrm{mg} / \mathrm{L}$ se presentó una disminución de la absorbancia a medida que aumentaba la concentración de fenol, Figura 6.

Las muestras llamadas "preenriquecimiento" se mantuvieron en bajos niveles de absorbancia con excepción de $500 \mathrm{mg} / \mathrm{L}$ de fenol en la muestra de suelo. Lo anterior, al compararlo con las muestras llamadas "adaptadas" y "directas" que van directamente a medio mineralizado con la fuente de carbono de fenol, presentaron aumentos de absorbancias, prevaleciendo las muestras de suelo en 200 y $500 \mathrm{mg} / \mathrm{L}$.

Al observar las tendencias de las muestras llamadas "adaptadas" y "preenriquecimiento", de agua de bahía y suelo, en todas las concentraciones de fenol estudiadas de 200, 500, 1000, 3000, 5000, y $10000 \mathrm{mg} / \mathrm{L}$ y en tres días de seguimiento, las absorbancias se comportan semejantes, con excepción en "adaptada" de la muestra de suelo con $200 \mathrm{mg} / \mathrm{L}$ de fenol, cuya curva se apartó con niveles de absorbancia mayores. Así mismo, en "preenriquecimiento" hubo un aumento súbito de la absorbancia al tercer día en la muestra de suelo con 500mg/L de fenol, Figura 7 .

Screening de crecimiento bacteriano en medios sólidos. Para el recuento de bacterias pre adaptadas a las diferentes concentraciones de fenol descritas anteriormente, se partió de los crecimientos en medio mineralizado sembrados con muestra líquida de agua (bahía) y muestra sólida (suelo), procedimiento "adaptada" y "preenriquecimiento", donde se hicieron los siguientes procedimientos:
Repiques de los erlenmeyer de $250 \mathrm{ml}$, que contenían $50 \mathrm{ml}$ de caldo mineralizado con concentraciones de fenol de 200 a $10000 \mathrm{mg} / \mathrm{L}$, del procedimiento "adaptada", sobre agar nutritivo y agar mineralizado. Sobre el agar mineralizado, la muestra líquida de agua (bahía), presentó crecimientos abundantes (conteos mayores de 300 colonias) en la concentración de $200 \mathrm{mg} / \mathrm{L}$, mientras que en la concentración de $500 \mathrm{mg} / \mathrm{L}$ se presentaron 52 colonias, siendo negativas las demás concentraciones. La muestra de suelo presento crecimientos hasta la concentración de $1000 \mathrm{mg} / \mathrm{L}$. Los crecimientos sobre agar nutritivo fueron abundantes hasta la concentración de $1000 \mathrm{mg} / \mathrm{L}$ tanto en la muestra líquida de bahía como la de suelo. El agar mineralizado permitió la diferenciación, Figura 8 y 9.

Recuento de microorganismos de todos los erlenmeyer con caldo mineralizado a las diferentes concentraciones de fenol y con los procedimientos de "adaptado" y "preenriquecimiento", una vez terminado el tiempo de incubación de la última concentración de $10000 \mathrm{mg} / \mathrm{L}$. En el procedimiento de "preenriquecimiento" con la muestra líquida de bahía, crecieron hasta $500 \mathrm{mg} / \mathrm{L}$ siendo menor el número de colonias que en $200 \mathrm{mg} / \mathrm{L}$. Mientras que en la muestra sólida de suelo el crecimiento se dio hasta $1000 \mathrm{mg} / \mathrm{L}$. Así mismo, con el procedimiento "adaptada", con la muestra líquida de bahía, crecieron abundantemente hasta $1000 \mathrm{mg} / \mathrm{L}$, manifestándose ya una coloración verdosa clásica del género Pseudomonas. Por su parte en la muestra sólida de suelo, el crecimiento masivo se dio hasta $1000 \mathrm{mg} / \mathrm{L}$, con un crecimiento de 236 colonias a la concentración de $3000 \mathrm{mg} / \mathrm{L}$, Figuras 10 y 11.

\section{Discusión}

El uso de bacterias puras para procesos de bioremediación(4) y su adaptación a concentraciones de la sustancia a estudiar, como en el caso de fenol, y donde los procesos aérobicos u oxigénicos son relevantes $(12,17)$, así como la pre adaptación que aumenta eficiencia (12), se consideran aspectos fundamentales en procesos de biodegradación con fines de tratamiento biológico de aguas, suelos o aire contaminado con sustancias químicas. 

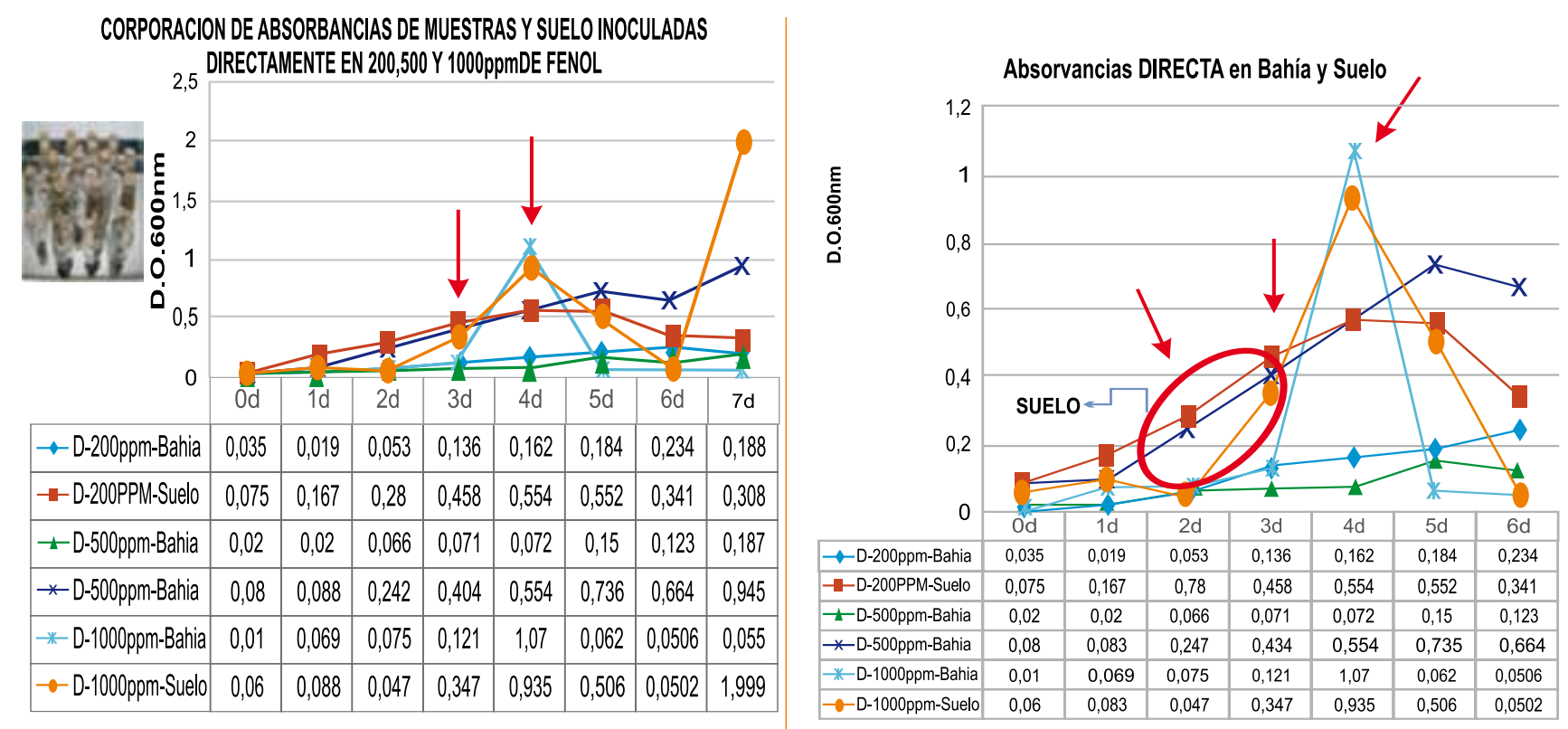

Figura 5. Absorbancias en muestras de bahía y suelo con concentraciones de 200, 500 y $1000 \mathrm{mg} / \mathrm{L}$ y procedimiento directo.

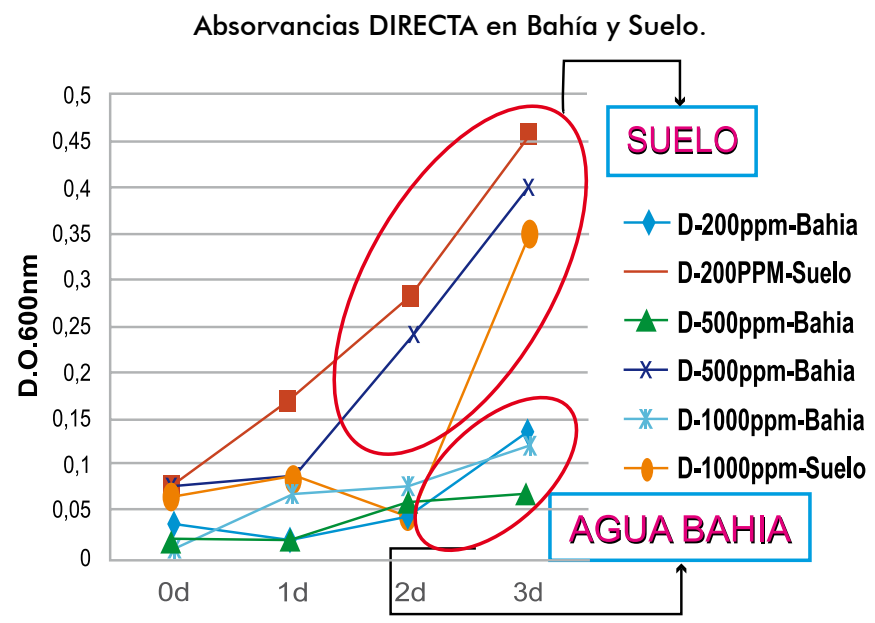

Absorvancias ADAPTADO en Bahía y Suelo.

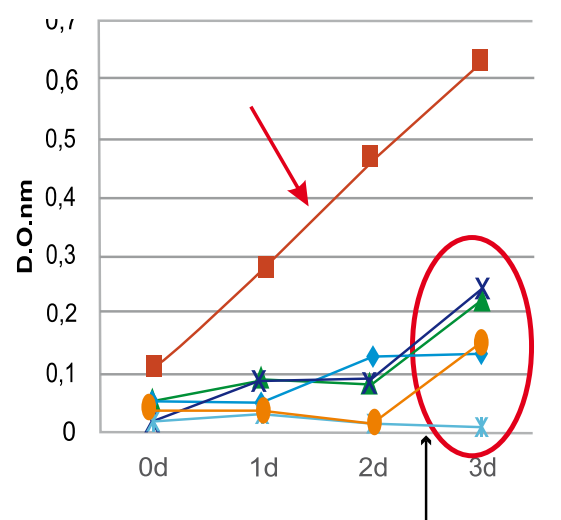

Absorvancias PREENRIQUECIMIENTO en Bahía y Suelo.

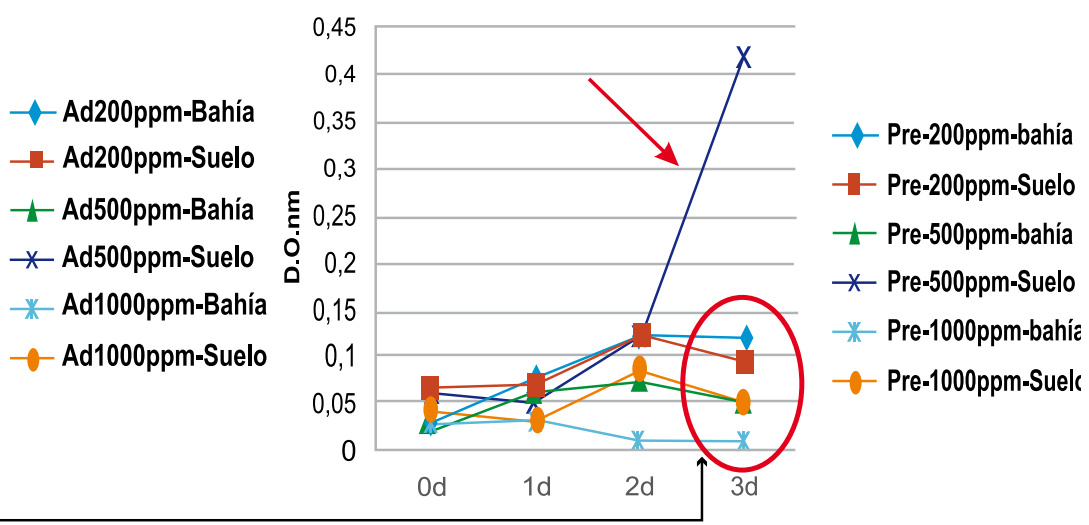

Figura 6. Absorbancias en muestras de bahía y suelo con concentraciones de 200, 500, 1000, 3000, 5000 y $10000 \mathrm{mg} / \mathrm{L}$ en procedimientos Directo, Adaptado y Pre-enriquecimiento. 


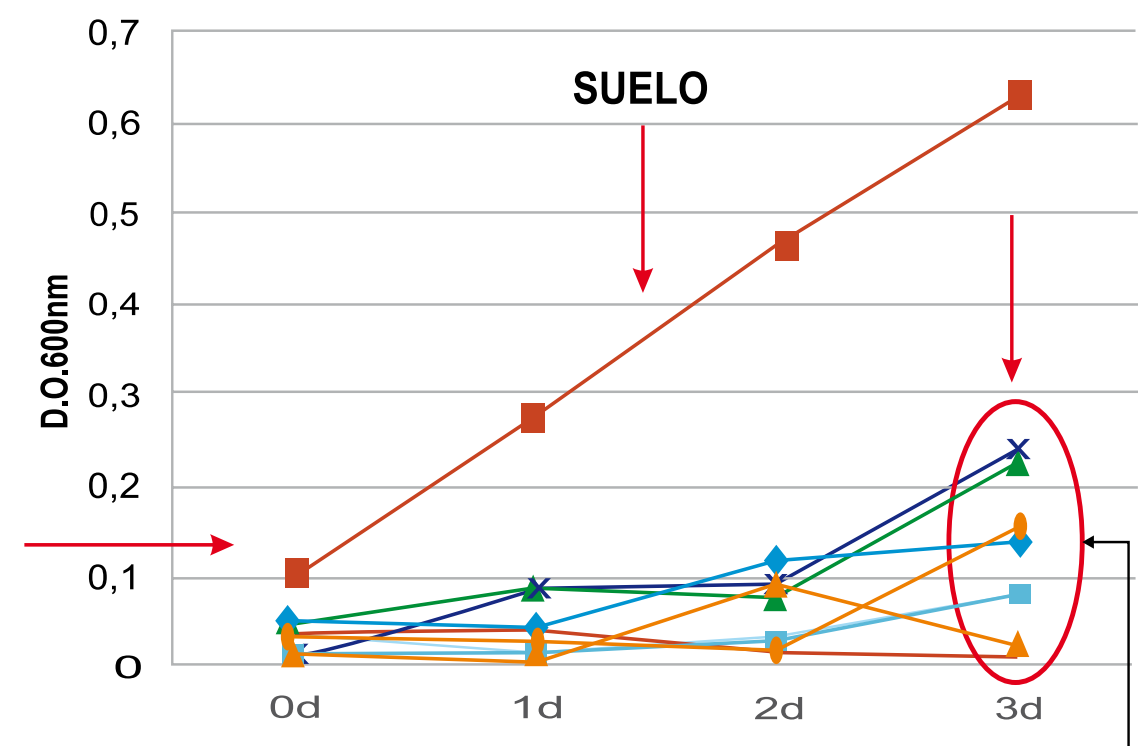

$\neg$ Ad200ppm-Bahía

$\rightarrow$ Ad200ppm-Suelo

$\leftarrow$ Ad500ppm-Bahía

* Ad500ppm-Suelo

* Ad1000ppm-Bahía

$\rightarrow$ Ad1000ppm-Suelo

- Ad3000ppm-Bahía

- Ad3000ppm-Suelo

- Ad5000ppm-Bahía

$\rightarrow$ Ad5000ppm-Suelo

Ad10000ppm-Bahia

- Ad10000ppm-Suelo

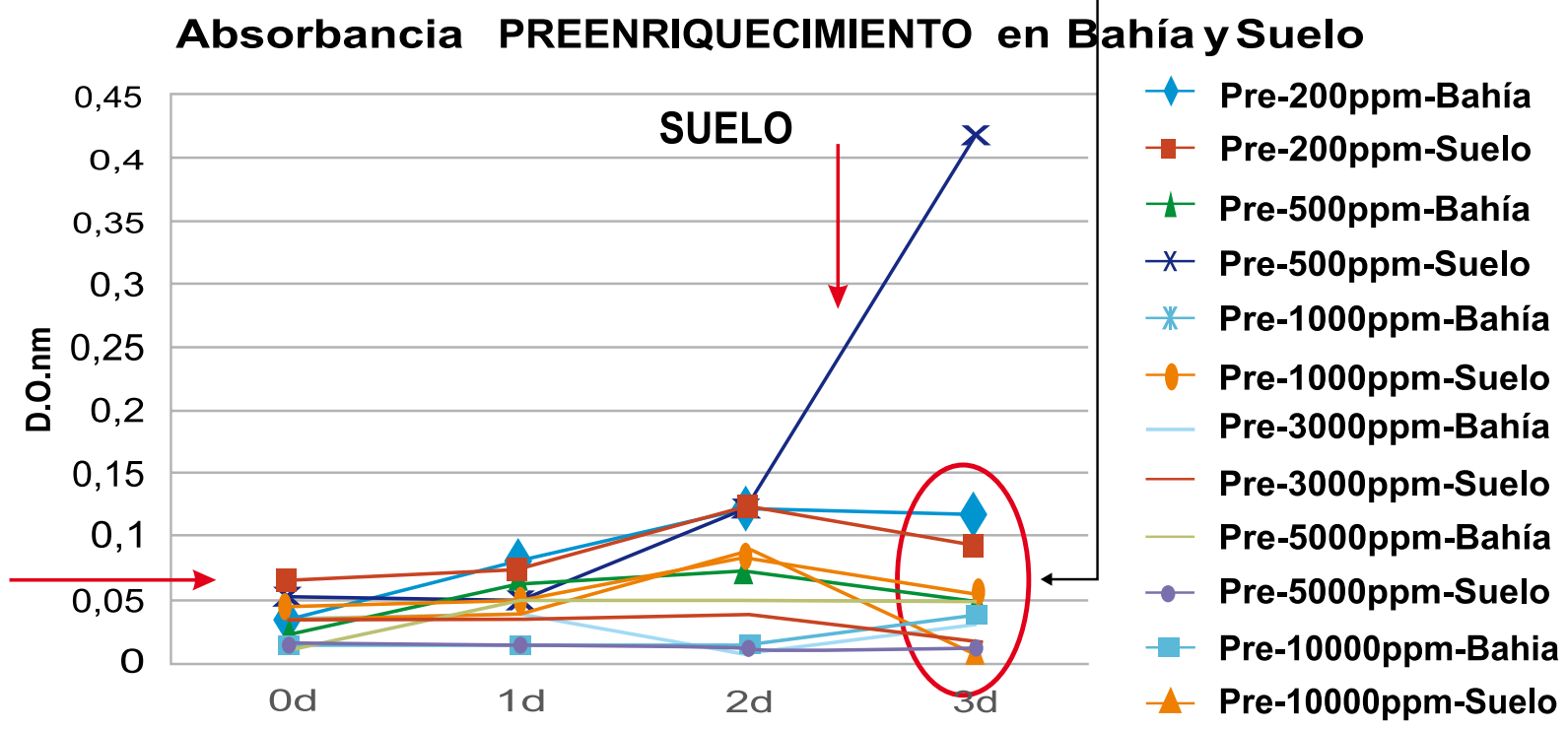

Figura 7. Absorbancias en muestras de bahía y suelo con concentraciones de 200, 500, 1000, 3000, 5000 y $10000 \mathrm{mg} / \mathrm{L}$ en procedimientos Adaptado y Preenriquecimiento.

El crecimiento de microorganismos en un medio mineralizado (7) con diferentes concentraciones de fenol $(14,18)$, permitió demostrar crecimientos entre 200 y $1000 \mathrm{mg} / \mathrm{L}$ en una semana de seguimiento y mayores absorbancias con muestras de suelo contaminado comparado con las de agua de bahía, explicando este hecho por los mayores agregados bacterianos; al observar los resultados de absorbancias y teniendo en cuenta las curvas de crecimiento bacteriano, hay una tendencia de fase estacionaria hacia el cuarto día, donde se pueden ver las curvas claras, permitiendo deducir que después de este día, se presentan datos que se salen de los esquemas establecidos en una curva de este tipo normal. Así mismo en las muestras llamadas "preenriquecimiento", se mantuvieron en bajos niveles de absorbancia con excepción de $500 \mathrm{mg} / \mathrm{L}$ de fenol en la muestra de suelo, posiblemente porque se hizo en caldo nutritivo, y al inocular a las 24 horas los caldos mineralizados, cambiaron drásticamente de una fuente rica en nutrientes a un medio restringido, lo que permitió atenuar su metabolismo, concluyéndose que a mayor concentración $(500$ y $1000 \mathrm{mg} / \mathrm{L})$ hay un mayor tiempo de adaptabilidad; el procedimiento adaptada, presento mayor diferenciación de absorbancia al tercer día de incubación, corroborado con crecimientos en medios sólidos a estas concentraciones de fenol, 


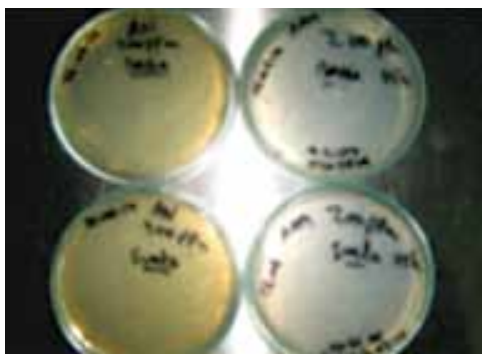

$200 \mathrm{ppm}$

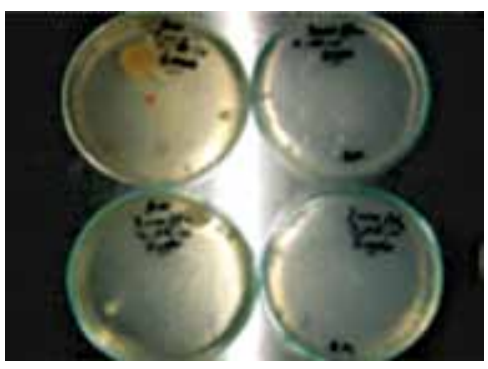

$3000 \mathrm{ppm}$

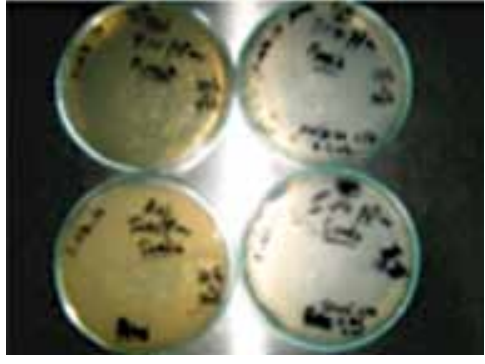

500 ppm

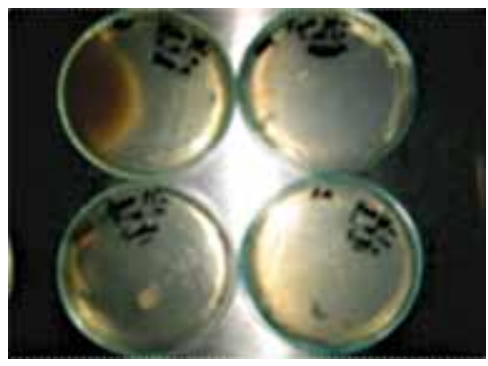

5000 ppm

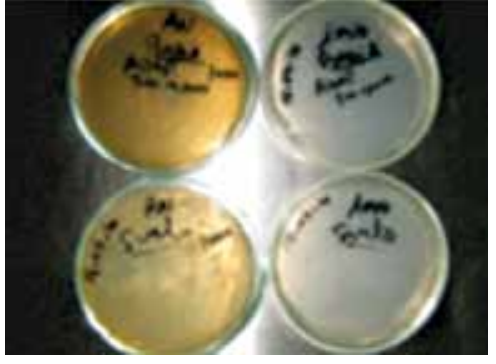

1000 ppm

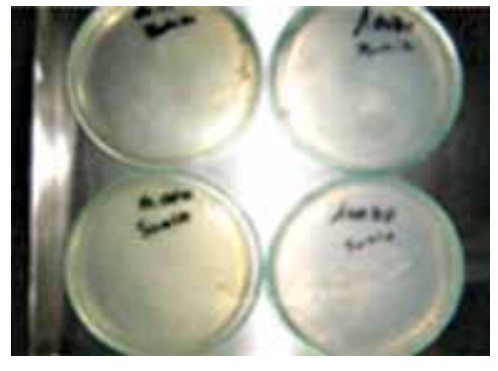

10000 ppm

Figura 8. Repiques de los caldos mineralizados sobre agar mineralizado y agar nutritivo al finalizar 72 h de incubación en cada una de las concentraciones de fenol, procedimiento Adaptado.

donde hubo crecimientos hasta $3000 \mathrm{mg} / \mathrm{L}$, hecho que merece más la profundización, en donde se puedan hacer aislamientos, recuentos e identificación de los microorganismos crecidos en diferentes concentraciones de fenol.

La variación de siembra directa, evidencia ser un buen método de inoculo, pues los microorganismos pre adaptados en un suelo contaminado y con mayor carga bacteriana, no experimentan estrés al llevarlos a un medio mineralizado con concentraciones de

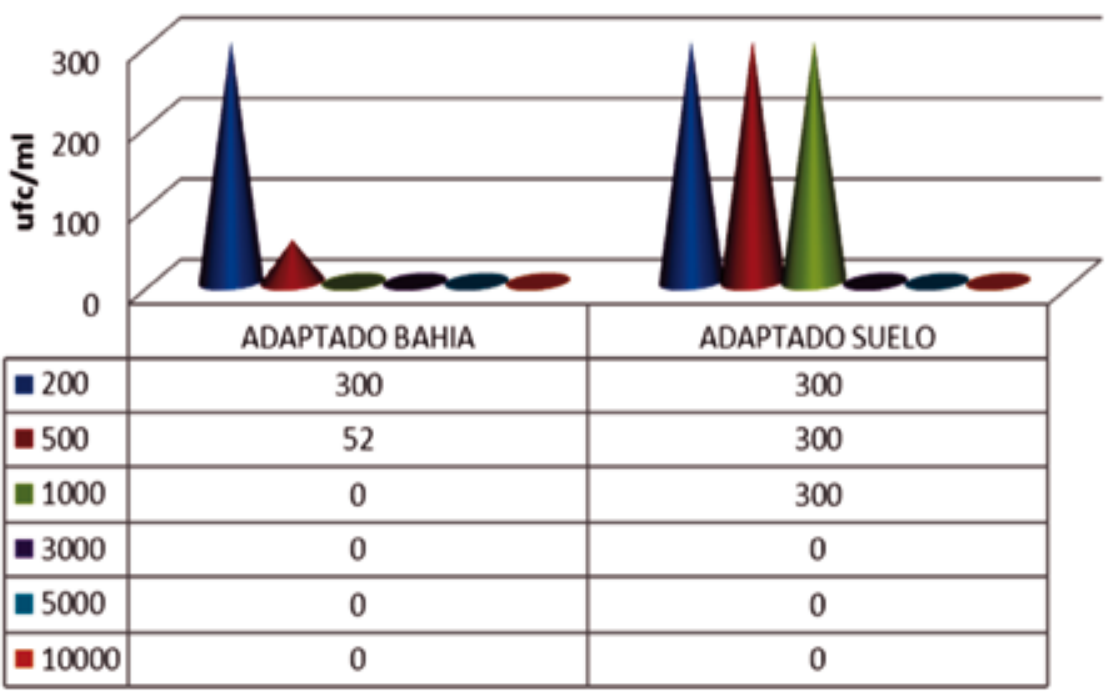

Figura 9. Conteo de colonias sobre agar mineralizado al finalizar $72 \mathrm{~h}$ de incubación en cada una de las concentraciones de fenol, procedimiento Adaptado.
200 y $500 \mathrm{mg} / \mathrm{L}$. Los tres días de incubación son suficientes para evidenciar un comportamiento de los microorganismos frente al reto de adaptación en concentraciones de 200 y $500 \mathrm{mg} / \mathrm{L}$.

No hay claridad en el experimento para mostrar con las variaciones de siembra (directa, adaptada y preenriquecimiento), la escogencia de un método para muestras de agua contaminadas y con baja carga de microorganismos; sólo el adaptado que mostró crecimiento a $500 \mathrm{mg} / \mathrm{L}$, habiendo diferenciación al tercer día.

Estos resultados son el inicio de muchos estudios que permitirán profundizar en el conocimiento de los procesos de biodegradación de fenol, como:

(i)Seguimiento y caracterización morfológica, bioquímica y molecular de microorganismos adaptados en concentraciones de 200-3000mg/L de fenol, (ii) 
ADAPTADO
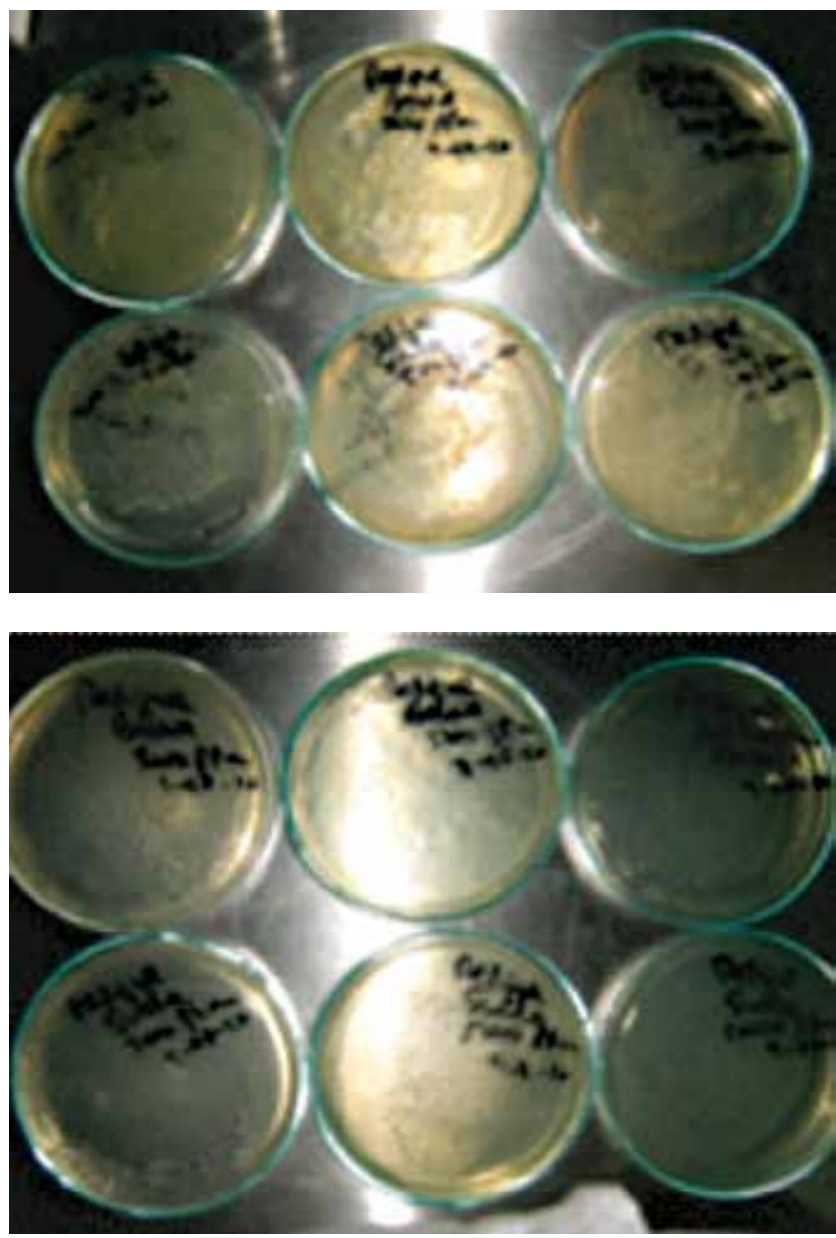

PRE-ENRIQUECIMIENTO
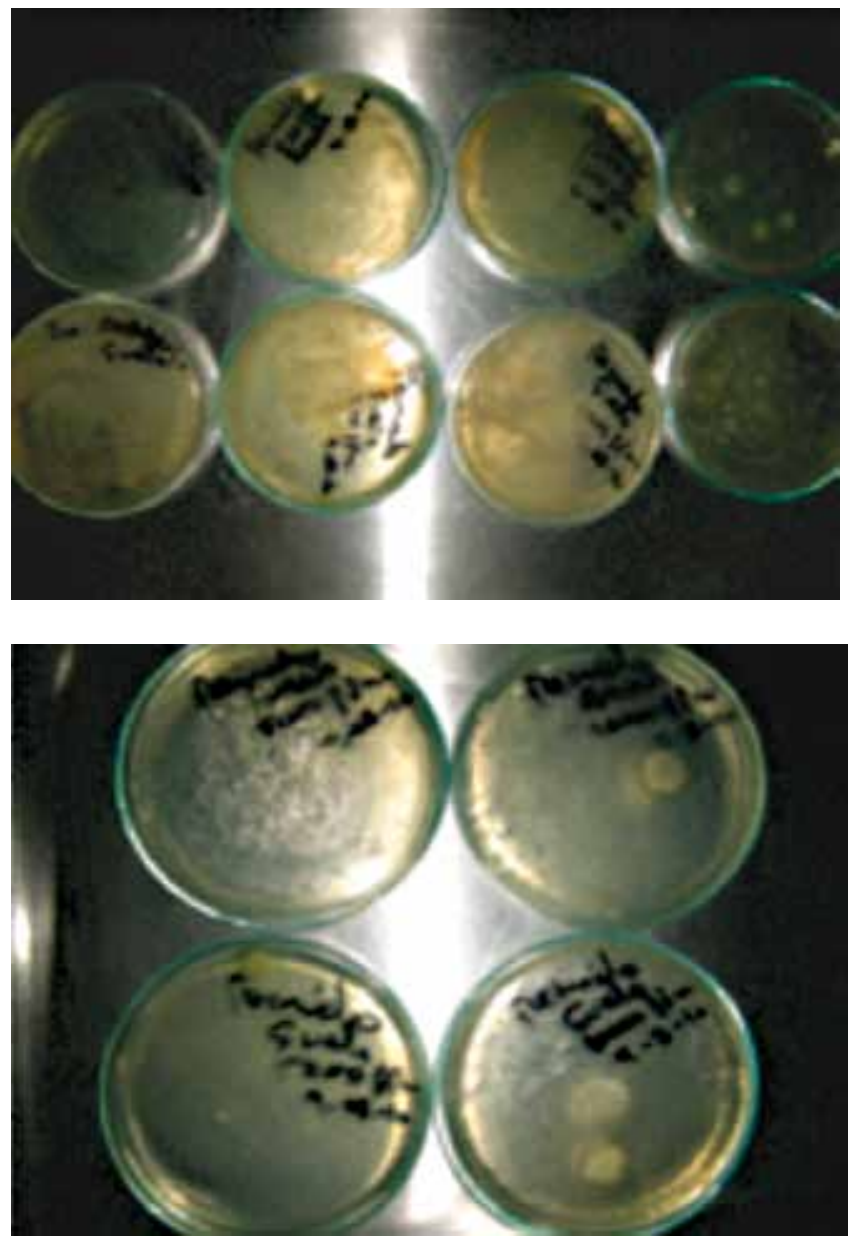

Figura 10. Repiques de los caldos mineralizados sobre agar nutritivo al finalizar la concentración de fenol de $10000 \mathrm{mg} / \mathrm{L}$, en procedimiento Adaptado y Preenriquecimiento

Figura 11. Conteo de colonias de Bahía y Suelo sobre agar nutritivo al finalizar la última concentración de fenol, procedimiento Adaptado y Preenriquecimiento. 
Estudios de biodegradación de microorganismos adaptados a diferentes concentraciones de fenol, (iii) Inmovilización de microorganismos adaptados a diferentes concentraciones de fenol, (iv) ensayos en biofiltros para la depuración de aguas residuales industriales contaminadas con fenol.

\section{Agradecimientos}

Se agradece a la Universidad San BuenaventuraCartagena por la financiación de este estudio, así como a todo el personal del Laboratorio y a la estudiante de Bacteriología Johana Arroyo.

\section{Referencias}

1. Chi-Wen, L., Chia-Hsien, Y.,Shen-Long.T.Biotreatment of phenolcontaminated wastewater in a spiral packed-bed bioreactor. Bioprocess BiosystEng.2009(32):575-580.

2. Jiang, H,TayJand Tay, S.Aggregation of immobilized activated sludge cells into aerobically grown microbial granules for the aerobic biodegradation of phenol. Letters in Applied Microbiology. 2002(35): 439-445.

3. Gurusamy, A., Ruey-Shin, J. and Duu-Jong, L. Biodegradation and adsorption ofphenol using activated carbon immobilized with Pseudomonas putida. J. Environ. Sci. Health, A. 2002(37):1133-1146.

4. Begonña,M, Hidalgo, A, Serra, JL, Llama, MJ. Degradation of phenol by RhodococcuserythropolisUPV-1 immobilized on Biolite in a packed-bed reactor.Journal of Biotechnology. 2002(97): 1-11.

5. Godjevargova, T,Ivanova, D, Alexieva, Z, Dimova, N. Biodegradation of toxic organic components from industrialphenol production waste waters by free and immobilizedTrichosporoncutaneum R57. Process Biochemistry. 2003(38) 915-/920.

6. Diomi, M., Emmanuel, K., Nikolaos, P., Dimitris G., Hatzinikolaou, P. Biodegradation of Phenol by Acclimatized Pseudomonas putida Cells Using Glucose as an Added Growth Substrate. Journal of Environmental Science and Health Part A-Toxic/Hazardous Substances \& Environmental Engineering. 2004 (39): 2093-2104.
7. Arutchelvan,V, Kanakasabai, V, Elangovan,R,Nagarajan, S,Muralikrishnan, V.Kinetics of high strength phenol degradation using Bacillus brevis.Journal of Hazardous Materials B. 2006(129) 216-222.

8. Vidya,K, Kalifathulla, I, Srinikethan,G.Performance of pulsed plate bioreactor for biodegradation of phenol. Journal of Hazardous Materials. 2007(140):346-352.

9. Dipty, S., Fulekar,MH. Bioremediation of Phenol Using Microbial Consortium InBioreactor.Innovative Romanian Food Biotechnology (2007): 1-11.

10. Ruiz, N, Ruiz, JC, Castañón, JH, Hernández, E, Cristiani, E, y Galíndez, J.PhenolBiodegradationUsing a RepeatedBatch Culture ofCandidatropicalisin a MultistageBubbleColumn. RevistaLatinoamericana de Microbiología2001(43):19-25.

11. Khaled,M.Biodegradation of Phenol by Actinobacillus Sp.: Mathematical Interpretation and effect of some growth condititions.Bioremediation Journal. 2007 (11):103-12.

12. Kyung Han Kwon Æ Sung Ho Yeom. Optimal microbial adaptation routes for the rapid degradation of high concentration of phenol. BioprocessBiosystEng (2009) 32:435-442.

13. Morlett, JA, Ascacio, JA, Rivas, AM, Velázquez, JF,Haskins, W, Barrera, HA, Acuña, K. Kinetics of BTEX biodegradation by a microbial consortium acclimatized to unleaded gasoline and bacterial strains isolated from it. International Biodeterioration \& Biodegradation. 2010(64): 581-587.

14. Yan, J, Jianping, W, Jing, B, Xiaoqiang, J, Zongding, H. Biodegradation of phenol at high initial concentration by Alcaligenesfaecalis.Journal of HazardousMaterials.2007(147): 672-676.

15. Vidya,K., Ramanjaneyulu, R, Srinikethan,G.Biological phenol removal using immobilized cells in a pulsed plate bioreactor: Effect of dilution rate and influent phenol concentration.Journal of Hazardous Materials. (2007b).

16. Echeverri, G. et al. Aislamiento de bacterias potencialmente degradadoras de petróleo en hábitats de ecosistemas costeros en la bahía de Cartagena, Colombia. Revista Nova. 2011( 8): 92-102.

17. Jiangya, Z, Xiaojuan, Y, Cong, D, Zhiping W, Qianqian, Z, Hao, P, Weimin, C. Optimization of phenol degradation by Candida tropicalisZ-04 usingPlackett-Burman design and response surface methodology. Journal of Environmental Sciences. 2011(23):22-30.

18. Plackett-Burman.Design and Response SurfaceMethodology. Journal of Environmental Sciences. 2011( 23) 22-30.
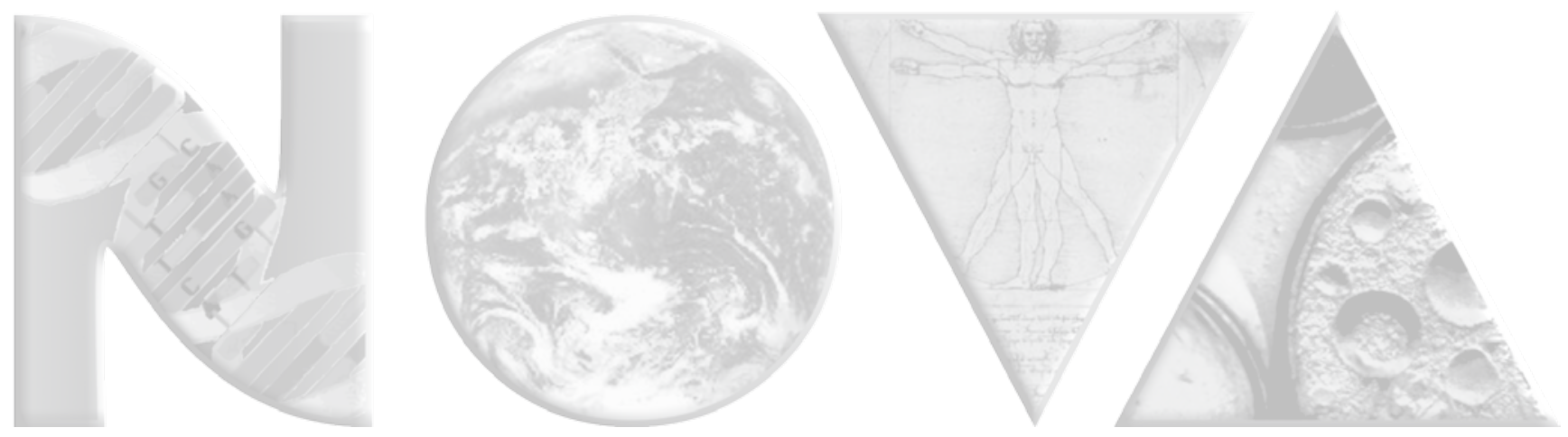